\title{
An Aberrant Line on CT Head: The Mendosal Suture
}

\author{
Jigish Ruparelia ${ }^{1}$ Rajnish Patidar ${ }^{1} \quad$ Jaskaran Singh Gosal ${ }^{1}$ Mayank Garg ${ }^{1}$ \\ Suryanarayanan Bhaskar ${ }^{1}$ Deepak Kumar Jha ${ }^{1}$
}

${ }^{1}$ Department of Neurosurgery, All India Institute of Medical

Sciences, Jodhpur, Rajasthan, India

\begin{abstract}
Address for correspondence Jaskaran Singh Gosal, MCh, Department of Neurosurgery, All India Institute of Medical Sciences, Jodhpur, Rajasthan 342005, India

(e-mail: jhsgosal_87@hotmail.com).
\end{abstract}

\begin{abstract}
Keywords

- computed tomography

- craniofacial

- imaging

- neuroanatomy
\end{abstract}

\section{,Introduction}

A knowledge of variant anatomy is often as important in clinical practice as is being familiar with the normal anatomy. This helps clinicians be wary of overdiagnosing a pathology when there is, in fact, none. Skull radiographs often reveal such variances, especially in newborns and young children. This holds especially true for the occipital bone where accessory sutures have been described. ${ }^{1}$

We recently treated a 14-year-old with chronic mastoiditis and consequent left-sided cerebellar abscess. Left suboccipital craniotomy, drainage of the abscess, as well as mastoidectomy was done. The child recovered well postsurgery. However, retrospective analysis of the head CT (including 3D reconstruction by VRT [volume rendering technique]) revealed a well-developed accessory occipital suture running from one asterion to the other, and dividing the occipital bone into a superior and an inferior part - Fig. 1. This suture, also called the mendosal suture (from Latin mendosus meaning "faulty" or "incorrect") or the transverse occipital suture, has been found in up to $3 \%$ of the Indian population, ${ }^{1}$ and up to $14 \%$ in other postmortem studies. ${ }^{2}$ However, most of these skulls have sutures that are either unilateral or bilateral but discontinuous at the midline. ${ }^{2}$ They are also usually described only in children below the age of 6 years. ${ }^{3}$ We reported an extremely rare case of a complete mendosal suture.

The occipital bone develops from six ossification centers in utero. Most of them fuse by the time of birth. Mendosal suture is seen due to incomplete or improper fusion of the interparietal (planum occipitale) and supraoccipital (planum nuchale) portions of the occipital bone. This results in an outward convex bulge of the midportion of the occipital bone, called bathrocephaly, as is seen in our patient. ${ }^{4}$ It may easily be confused with fracture lines if the clinician is unaware of this normal variation. ${ }^{5,6}$ However, accessory sutures make a zig-zag pattern with interdigitations and have sclerotic borders similar to major calvarial sutures. ${ }^{7}$ They are also often bilateral and symmetrical. Fracture lines, on the other hand, have sharp lucencies with nonsclerotic edges and have associated soft tissue swelling or hematoma. Furthermore, the mendosal suture can be confused with lambdoid suture while searching for asterion during retromastoid suboccipital craniotomy, and its existence should therefore be known to all the neurosurgeons. 

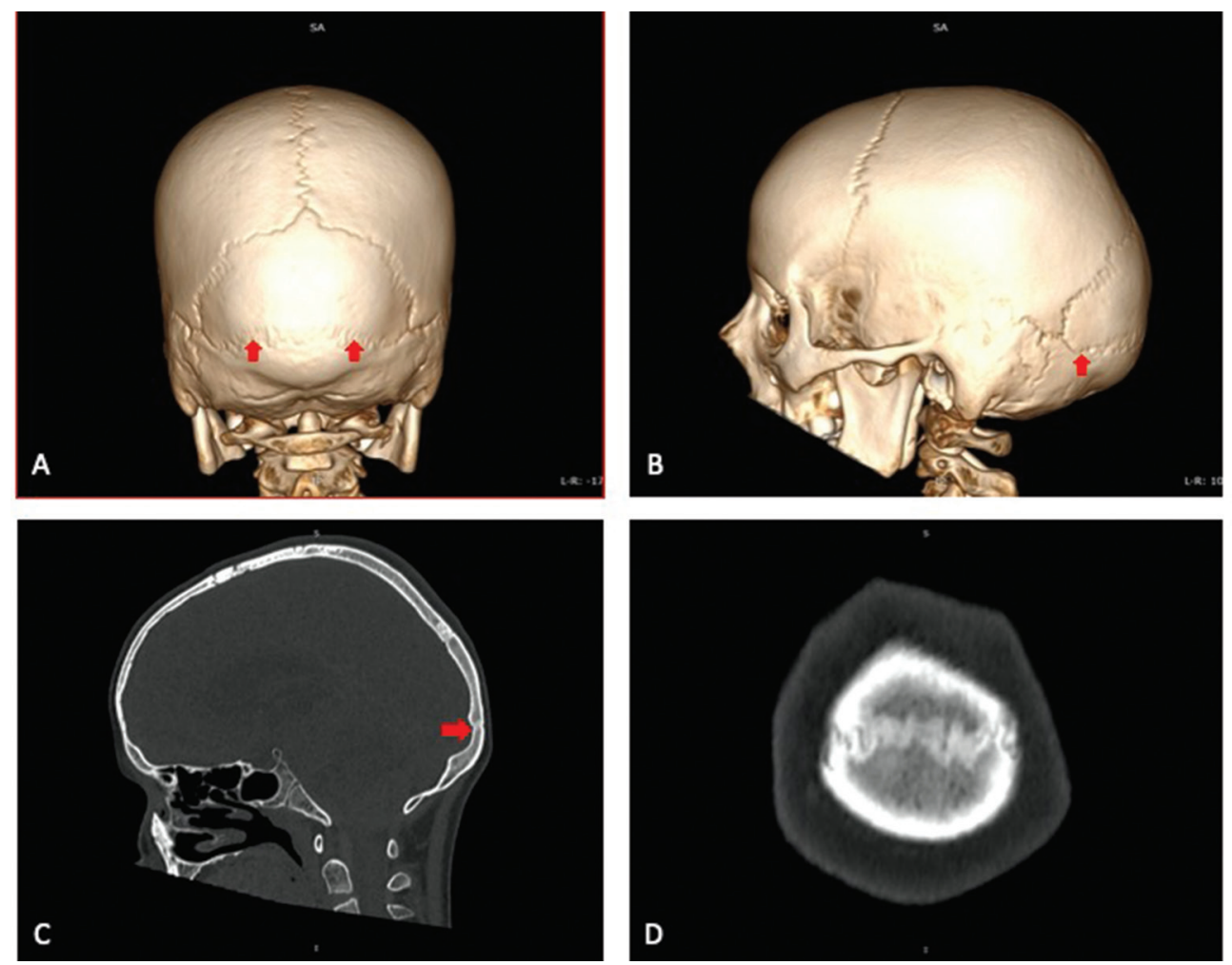

Fig. 1 (A) 3D VRT image showing the mendosal suture (arrow) when viewing the skull from behind. (B) Lateral VRT projection showing the suture (arrow). (C) Sagittal CT bone window showing the mendosal suture (arrow) distinct from the lambdoidal suture seen above. (D) Coronal CT bone window showing that this suture ran the whole distance from one asterion to another. Abbreviation: VRT, volume rendering technique.

\section{Conflict of Interest}

None declared.

\section{References}

1 Nayak SR, Krishnamurthy A, Madhan Kumar SJ, et al. The mendosal suture of the occipital bone: occurrence in Indian population, embryology and clinical significance. Surg Radiol Anat 2007;29(4):329-332

2 Gayretli O, Gurses IA, Kale A, et al. The mendosal suture. Br J Neurosurg 2011;25(6):730-733

3 Idriz S, Patel JH, Ameli Renani S, Allan R, Vlahos I. CT of normal developmental and variant anatomy of the pediatric skull: distinguishing trauma from normality. Radiographics 2015;35(5):1585-1601

4 Smith LGF, Governale LS, Sribnick EA. A persistent mendosal suture presenting with bathrocephaly. Pediatr Neurol 2017;73:110

5 Naldemir IF, Guclu D, Baki Altınsoy H, Berk Canga H, Onbas O. Accessory occipital suture mimicking fracture in head trauma. Am J Emerg Med 2018;36(3):530.e7-530.e8

6 Nakahara K, Miyasaka Y, Takagi H, Kan S, Fujii K. Unusual accessory cranial sutures in pediatric head trauma-case report. Neurol Med Chir (Tokyo) 2003;43(2):80-81

7 Choudhary AK, Jha B, Boal DK, Dias M. Occipital sutures and its variations: the value of 3D-CT and how to differentiate it from fractures using 3D-CT? Surg Radiol Anat 2010;32(9):807-816 